\title{
Effect of annealing treatment on the microstructure, mechanical and tribological properties of chromium carbonitride coatings
}

\author{
Linda Aissani $^{\mathrm{a}, \mathrm{b}, *}$, Mamoun Fellah ${ }^{\mathrm{b}, \mathrm{c}}$, Lamia Radjehi ${ }^{\mathrm{a}, \mathrm{d}}$, Corinne Nouveau ${ }^{\mathrm{e}}$, Alex Montagne ${ }^{\mathrm{f}}$, \\ Akram Alhussein ${ }^{\mathrm{d}, * *}$ \\ ${ }^{a}$ Materials Sciences Department, ABBES Laghrour-Khenchela University, P.O 1252, 40004, Algeria \\ ${ }^{\mathrm{b}}$ Materials and Tribology Group, Laboratory of Foundry, Annaba University, BO, 12, CP 23000, Algeria \\ ${ }^{\mathrm{c}}$ Mechanical Engineering Department, ABBES Laghrour-Khenchela University, P.O 1252, 40004, Algeria \\ ${ }^{\mathrm{d}}$ ICD-LASMIS, Université de Technologie de Troyes, CNRS, Antenne de Nogent, Pôle Technologique de Sud Champagne, 26 Rue Lavoisier, 52800 Nogent, France \\ ${ }^{\mathrm{e}}$ Arts et Métiers ParisTech, La.Bo.Ma.P, Rue Porte de Paris, F-71250 Cluny, France \\ ${ }^{\mathrm{f}}$ Arts et Métiers ParisTech, Mechanics Surfaces and Materials Processing Laboratory, 8, Boulevard Louis XIV, F-59046 Lille Cedex, France
}

\section{A R T I C L E I N F O}

\section{Keywords:}

$\mathrm{Cr}-\mathrm{N}$

$\mathrm{Cr}-\mathrm{C}$

$\mathrm{Cr}-\mathrm{C}-\mathrm{N}$

Annealing treatment

Diffusion

Microstructure

Tribological, mechanical properties

\begin{abstract}
A B S T R A C T
Chromium nitrides were deposited by $\mathrm{RF}$ reactive magnetron sputtering from a $\mathrm{Cr}$ target on high carbon steel substrates XC100 ( $1.17 \mathrm{wt} \%$ carbon) in a $\mathrm{N}_{2}$ and Ar gas mixture. In order to investigate the formation of chromium nitrides, carbide and carbonitride compounds were subjected to vacuum annealing treatment for $1 \mathrm{~h}$ at various temperatures ranging from 700 to $1000^{\circ} \mathrm{C}$. The samples were characterized by EDS, XPS, XRD, SEM, nanoindentation and tribometry. The results showed the emergence of $\mathrm{Cr}_{2} \mathrm{~N}$ and $\mathrm{CrN}$ during the early stages of annealing and the appearance of chromium carbonitride phases only at $900^{\circ} \mathrm{C}$. The (111) preferred orientation of the fcc CrN phase was changed to (002) at $900{ }^{\circ} \mathrm{C}$ in parallel with the appearance of chromium carbides. Nanoindentation tests revealed a gradual increase of the Young's modulus from 198 to $264 \mathrm{GPa}$ when increasing the annealing temperature, while the hardness showed a maximum value $(\mathrm{H}=22.4 \mathrm{GPa})$ at $900{ }^{\circ} \mathrm{C}$. The low friction coefficient of the $\mathrm{Cr}-\mathrm{C}-\mathrm{N}$ coating against a $100 \mathrm{Cr} 6$ ball was approximately 0.42 at $900{ }^{\circ} \mathrm{C}$. The enhancement of mechanical and tribological properties was attributed to the stronger bonding $\mathrm{Cr}-\mathrm{C}$ at the $\mathrm{CrN}$ / XC100 interfaces as confirmed by XPS results.
\end{abstract}

\section{Introduction}

Chromium thin films with exclusive super saturationed metalloid elements such as carbon or nitrogen have received wide technological interest due to their remarkable performance, such as high hardness, high elasticity modulus, good wear resistance and chemical stability under extreme conditions [1-4]. Nowadays, the most commonly used PVD coatings are chromium nitrides [5] and carbides [6]. These hard coatings $(H=15-40 \mathrm{GPa}, E=200-500 \mathrm{GPa})$ have a high wear resistance which is many times better than steel substrates. Chromium carbides and nitrides, each having several interesting properties, become very attractive candidates for protective coatings in industrial metal cutting tools. Concerning the chromium carbide coating, the presence of carbon in the chromium-based metal coating increases hardness and wear resistance by a lubricating effect [7]. The $\mathrm{Cr}_{7} \mathrm{C}_{3}$ is one of the $\mathrm{Cr}$ carbides having excellent corrosion and wear resistance and is used largely in severe environmental conditions [6-8]. Among the chromium nitrides, the $\mathrm{CrN}$ and $\mathrm{Cr}_{2} \mathrm{~N}$ are widely used for industrial applications because of their good hardness, high chemical stability and toughness [9-11].

Furthermore, improving mechanical properties and increasing the cutting speed limit of a machining tool are necessary for its durable performance. This requires new hard based chromium coatings with high thermal stability and good wear resistance under more severe workload conditions. Generally, the enhanced tribological and mechanical properties of sputtered binary chromium coatings can be achieved by varying the microstructure and chemical composition. This is typically controlled by the deposition parameters and the applied treatment [12]. Recently, researchers have developed coatings based on forming hard chromium phases embedded in the nitrogen in parallel with the carbon $(\mathrm{Cr}-\mathrm{C}$ and $\mathrm{Cr}-\mathrm{N})$ [9-11]. Many studies have been conducted to develop the mechanical properties of chromium-based

\footnotetext{
* Correspondence to: L. Aissani, Materials Sciences Department, ABBES Laghrour-Khenchela University, P.O 1252, 40004, Algeria.

** Correspondence to: A. Alhussein, ICD-LASMIS, Université de Technologie de Troyes, CNRS, 26 rue Lavoisier, 52800 Nogent, France.

E-mail addresses: lindaaissani2004@yahoo.fr (L. Aissani), akram.alhussein@utt.fr (A. Alhussein).
} 
coatings, especially hardness and wear resistance $[12,13]$. The presence of carbon will confine the grain growth of the chromium nitride phase, which inhibits the mobility of plastic deformation during solid-solid interactions $[14,15]$. The resulting chromium carbonitride phases combine the properties of chromium carbides (hardness and ductility) and chromium nitrides (hardness, wear and corrosion resistance). Tests of hardness, tribology behaviour, corrosion and thermal resistance showed that chromium carbonitride coatings have great potential for tool protection [9]. However, only limited reports on sputtered $\mathrm{Cr}-\mathrm{C}-\mathrm{N}$ coatings are available; these either discuss the microstructure and mechanical properties with different carbon content [10], or the influence of $(\mathrm{C}+\mathrm{N}) / \mathrm{Cr}$ ratio on the mechanical and tribological behaviour without comprehensive information on the chemical bonding structure [14].

In earlier experiments (to be published elsewhere) we found that our $\mathrm{Cr}-\mathrm{N}$ [12] and $\mathrm{Cr}-\mathrm{C}$ [6] films show rather high friction coefficients between 0.53 and 0.62 and correspondingly high wear rates. Therefore, in this paper, our objective is to improve the coating's mechanical and tribological behaviour by increasing the carbon content. We investigated the influence of the coating composition on the mechanical and tribological properties of $\mathrm{Cr}-\mathrm{C}-\mathrm{N}$ coatings, especially with regards to the diffusion of carbon from the substrate during annealing temperature and comparing the properties of $\mathrm{Cr}-\mathrm{N}$ and $\mathrm{Cr}-\mathrm{C}$ films. The present study is aimed at preparing, characterizing and testing $\mathrm{Cr}-\mathrm{C}-\mathrm{N}$ coatings with high hardness and high wear resistance. Therefore, the chemical composition and structure as well as mechanical and tribological properties of the annealed $\mathrm{Cr}-\mathrm{C}-\mathrm{N}$ coatings deposited by reactive magnetron sputtering were thoroughly presented.

\section{Experimental details}

\subsection{Film deposition}

High carbon steel samples (XC100 in the French standard AFNOR10027, containing $1.17 \mathrm{wt} \% \mathrm{C}$ ) were used to deposit chromium nitrides. The small disc substrates $\left(15 \times 3 \mathrm{~mm}^{2}\right)$ were initially polished to obtain an average roughness $R_{a}$ of about $30 \mathrm{~nm}$. Before deposition, all substrates were cleaned ultrasonically in acetone for $5 \mathrm{~min}$, and were then dried in hot air.

The RF reactive magnetron sputtering (NORDIKO type 3500, $13.56 \mathrm{MHz}$ ) was used to deposit $\mathrm{CrN}$ coatings. A chromium target ( $99.98 \%$ purity, $\varnothing 101.6 \times 3 \mathrm{~mm}^{2}$ ) was used and its distance from the substrate holder was kept constant at $80 \mathrm{~mm}$. The deposition chamber was pumped down to a low pressure $\left(<10^{-5} \mathrm{~Pa}\right)$. Prior to deposition, the substrates were sputter-cleaned for $5 \mathrm{~min}$ by argon plasma at $1 \mathrm{~Pa}$ and $-700 \mathrm{~V}$ in order to remove impurities. The deposition procedure was carried out, at $150{ }^{\circ} \mathrm{C}$, for $90 \mathrm{~min}$, under a reduced pressure of $0.4 \mathrm{~Pa}$ with an $\mathrm{N}_{2}$ (purity 99.999\%)/Ar (purity 99.999\%) ratio of 0.25 [12]. The electrical parameters applied to the $\mathrm{Cr}$ target and substrates were kept constant at $650 \mathrm{~W}$ and $-900 \mathrm{~V}$, respectively. The Cr-N/ XC100 samples were used for the evaluation of film structure, morphology, thickness, hardness, adhesion and friction coefficient.

\subsection{Heat treatment}

The Cr-N/XC100 samples were heat-treated under controlled vacuum at temperatures ranging from 700 to $1000^{\circ} \mathrm{C}$, in a tubular furnace. In order to study the effect of annealing temperature on the properties of the coatings, the thermal cycle started with an increase of $10^{\circ} \mathrm{C} / \mathrm{min}$, followed by maintaining at the desired temperature for $1 \mathrm{~h}$ at various fixed temperatures. Finally, cooling under controlled vacuum (about $-10^{\circ} \mathrm{C} / \mathrm{min}$ ) was done. The vacuum pressure of $10^{-5} \mathrm{~Pa}$, assured by a diffusion pump, was kept constant.

\subsection{Film morphology, chemical composition and microstructure analysis}

Film thicknesses and morphologies were observed by means of a scanning electron microscope (Jeol JSM-6400F, $10 \mathrm{kV}$ ), equipped with Energy dispersive spectroscopy (EDS) microanalysis to determine the chemical composition of the coating. The nature of the chemical bonds was investigated by X-ray photoelectron spectroscopy (Riber SIA 100 XPS). CasaXPS software tool was used for this analysis. The $\mathrm{K}_{\mathrm{\alpha Al}}$ radiation ( $\mathrm{h} \nu=1468.68 \mathrm{eV}, 300 \mathrm{~W})$ was applied as the excitation source. The vacuum in the spectrometer was $4 \times 10^{-8} \mathrm{~Pa}$. The spectrometer calibration was performed using binding energy level of $\mathrm{C} 1 \mathrm{~s}$ at $284.8 \mathrm{eV}$, which was absorbed on the surface of the samples. Then, the corresponding $\mathrm{Cr} 2 \mathrm{p}, \mathrm{N} 1 \mathrm{~s}$ and $\mathrm{C} 1 \mathrm{~s}$ spectra were fitted under a multipeak fitting method, and the ratio of Lorentzian to Gaussian was $20 \%$ [12].

The structure and phase composition of the coatings were assessed by X-ray diffraction (XRD) patterns using a Siemens D5000 X-ray $\theta-2 \theta$ apparatus applying $\mathrm{Co}_{\mathrm{K \alpha}}$ radiation $(\lambda=1.781 \AA$, $45 \mathrm{kV}$ and $40 \mathrm{~mA})$. The average crystalline size of the coatings was determined by Scherrer's method [12]:

$\mathrm{D}=\frac{0.9 \lambda}{\beta \cdot \cos \theta}$

where 0.9 is the shape factor, $\lambda$ represents the X-ray wavelength used for the measurement $\left(\lambda_{\mathrm{Co}}=0.178 \mathrm{~nm}\right), \beta$ is the line width (full width half maximum, FWHM) in radians and $\theta$ is the Bragg's angle. $\mathrm{The} \mathrm{Cr}_{2} \mathrm{~N}$ (200) and $\mathrm{Cr}_{7} \mathrm{C}_{3}$ (410) diffraction peak positions were used to estimate crystalline sizes.

\subsection{Mechanical and tribological characterizations}

The hardness and Young's modulus of $\mathrm{Cr}-\mathrm{N}$ films were determined by means of nanoindentation tests using a Nano Indenter XP from MTS, working with the Continuous Stiffness Measurement mode. By using a three-sided pyramidal diamond tip (Berkovich indenter), a maximum depth of $200 \mathrm{~nm}$ was considered, leading to a maximum load of approximately $10 \mathrm{mN}$. The loading and unloading of the indentations were carried out under loading control with a nominal rate of $0.05 \mathrm{mN}$ / s. Indentation curves were described by means of the general methodology for the films around $2 \mu \mathrm{m}$ thick [16].

To investigate the mechanical properties of the film/substrate interface zone, hardness and Young's modulus were determined by load-displacement data obtained by using a model MTS System equipped with Berkovich tip, performing 20 indentations per sample. The hardness measurements as a function of the film depth were performed on specimen's cross-sections going from the film surface zone to the steel substrate where indentation spacing was $0.2 \mu \mathrm{m}$.

The Young's modulus of the coating $\mathrm{E}$ is calculated with the following equation:

$\frac{1}{E}=\frac{\left(1-v_{i}^{2}\right)}{E_{i}}+\frac{\left(1-v_{m}^{2}\right)}{E_{m}}$

where $\mathrm{E}_{\mathrm{m}}$ and $\nu_{\mathrm{m}}$ are Young's modulus and Poisson's ratio for the specimen, $E_{\mathrm{i}}(1140 \mathrm{GPa})$ and $\nu_{\mathrm{i}}(0.07)$ are parameters proper to the Berkovich indenter.

The hardness and Young's modulus values for each depth position were obtained by averaging 3 indentations.

The roughness of film surface was measured by an atomic force microscope (AFM 100, APE research), operated in contact mode with a scan range of $3 \times 3 \mu \mathrm{m}^{2}$.

The tribological characterization was carried out by sliding wear tests using a tribometer (TRIBOtester) with a ball-on-disc configuration. Tests were carried out at ambient temperature with the following conditions: a 100Cr6 ball ( $\varnothing 6 \mathrm{~mm})$ was used as a counterpart, with an applied normal load of $2 \mathrm{~N}$ ( $>1 \mathrm{GPa}$ ), a sliding distance of $200 \mathrm{~m}$ and a constant speed of $5 \mathrm{~cm} \cdot \mathrm{s}^{-1}$. The morphology and composition of 


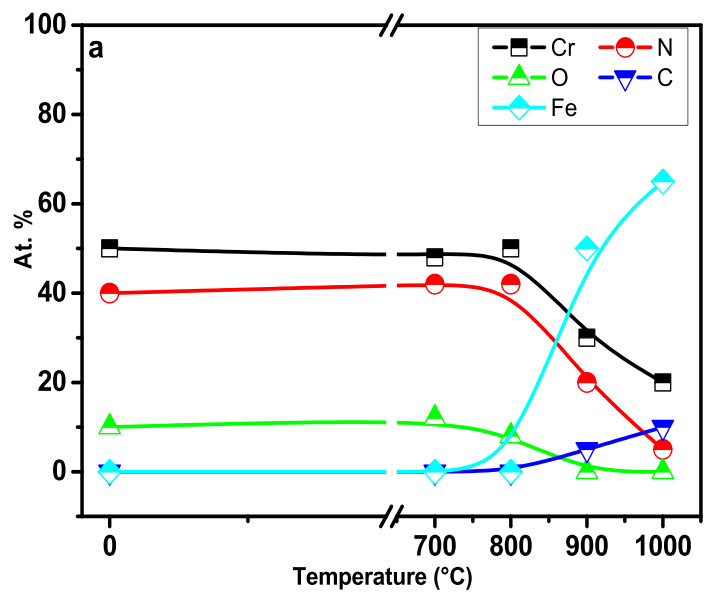

Fig. 1. Variation of $\mathrm{Cr}, \mathrm{Fe}, \mathrm{C}, \mathrm{N}$ and $\mathrm{O}$ composition as a function of annealing temperatures for $\mathrm{Cr}-\mathrm{N} / \mathrm{XC100}$ samples.

damaged samples were evaluated with an SEM equipped with an EDS. The wear volume and the surface roughness were determined with an optical profilometer (VEECO, Wyko-NT 1100) [16].

\section{Results and discussion}

\subsection{Structural characterization}

\subsubsection{Chemical composition}

In order to compare the properties of $\mathrm{Cr}-\mathrm{N}, \mathrm{Cr}-\mathrm{C}$ and $\mathrm{Cr}-\mathrm{N}-\mathrm{C}$ phases, it was necessary to prepare samples with the same conditions (e.g. deposition time). We investigated the influence of the annealing temperature on the variation of chemical composition of these samples. Fig. 1 shows the $\mathrm{Cr}, \mathrm{Fe}, \mathrm{N}, \mathrm{C}$ and $\mathrm{O}$ contents of Cr-N/XC100 coatings at different annealing temperatures measured by EDS. It can be seen that oxygen contamination is $<5$ at.\%. The main sources of oxygen impurity are probably the post-deposition contaminations and the annealing treatment carried out under mediocre vacuum. The oxygen concentration was reduced gradually as a function of increasing annealing temperature which leads to the decomposition of chromium oxides from $800^{\circ} \mathrm{C}$. The $\mathrm{Cr}$ and $\mathrm{N}$ concentrations changed slightly without $\mathrm{C}$ presence at $800^{\circ} \mathrm{C}$. This is attributed to the stability of chromium nitrides. At $T \geq 900{ }^{\circ} \mathrm{C}$, we can see a marked decrease in the $\mathrm{Cr}$ and $\mathrm{N}$ concentrations, which is more significant at $1000^{\circ} \mathrm{C}$. In contrast, we noticed a progressive increase in the $\mathrm{Fe}$ and $\mathrm{C}$ concentrations. This can be explained by the diffusion of $\mathrm{Cr}$ and $\mathrm{N}$ elements and their reactions with the $\mathrm{C}$ of the $\mathrm{XC} 100$ substrate at $1000{ }^{\circ} \mathrm{C}$ to form the chromium carbide and carbonitride phases [15].

Fig. 2 presents the evolution of N/Cr and C/Cr ratios as a function of the annealing temperatures. We can see that the $\mathrm{C} / \mathrm{Cr}$ ratio increased with an increasing annealing temperature. We obtained a $\mathrm{C} / \mathrm{Cr}$ ratio of 0.45 and 0.60 at 900 and $1000^{\circ} \mathrm{C}$, respectively. However, the $\mathrm{N} / \mathrm{Cr}$ ratio decreased between 900 and $1000{ }^{\circ} \mathrm{C}$ from 0.6 to 0.38 . This is mainly due to the disappearance of nitrogen in the $\mathrm{Cr}-\mathrm{N}$ system. Similar behaviour was observed on annealed $\mathrm{Zr} / \mathrm{XC100}$ samples [17].

Depth profiles obtained by XPS analysis at $900{ }^{\circ} \mathrm{C}$ showed that the composition of the coatings was heterogeneous throughout the thickness. The profiles present short-range discrepancy around a constant mean value for all the elements in the coatings (Fig. 3). In the middle of the interface zone, the profiles indicated that the carbon signal gained in intensity and reached a maximum value of about 20 at.\%. The carbon content decreased gradually between the middle and superficial regions confirming that its diffusion from the substrate occurred at this annealing temperature $\left(900^{\circ} \mathrm{C}\right)$. In the meantime, the intensity of chromium and nitrogen signals decreased in the interface zone. A slight degree of oxygen contamination was evident which probably originated

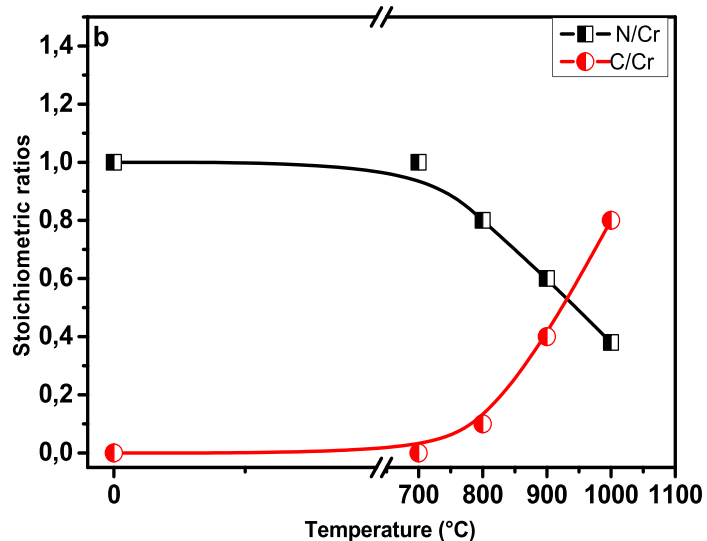

Fig. 2. Variation of stoichiometric ratios as a function of annealing temperatures for Cr-N/XC100 samples.

from some impurity. This oxygen contamination was confirmed previously by the X-ray microanalysis results (Fig. 1).

\subsubsection{Crystalline structure}

Fig. 4 presents the XRD patterns of coatings before and after heat treatment. Due to the small thickness of the coating deposited on the substrate, the $\mathrm{Fe}_{\alpha}$ intensity of the diffraction peaks is at a maximum. XRD analysis showed that the as-deposited coatings have a very shortrange order, where the small (111) and (200) diffraction lines at $44.32^{\circ}$ and $53.81^{\circ}$ correspond to $\mathrm{CrN}$ (cubic structure, JCPDS 00-011-0065). Also, (200) and (111) $\mathrm{Cr}_{2} \mathrm{~N}$ diffraction peaks can be observed at $47.99^{\circ}$ and $50.29^{\circ}$ (hexagonal structure, JCPDS 35 0803), which are similar to the observations in earlier studies [12,18]. In the early stages of the annealing treatment, all coatings were fully crystallized, as confirmed by the number of sharp peaks shown on Fig. 4. Between 700 and $800{ }^{\circ} \mathrm{C}$, there was a significant growth of $\mathrm{CrN}$ (111) and (200) signals, proving the stability of this nitride from $750{ }^{\circ} \mathrm{C}$ [19]. In addition, a new small (410) peak of $\mathrm{Cr}_{7} \mathrm{C}_{3}$ appears at $46.19^{\circ}$ (orthorhombic structure, JCPDS 00-006-0683), which confirms the beginning of the carbon diffusion from the substrate to the film.

As the annealing temperature increases to $900{ }^{\circ} \mathrm{C}$, (111) $\mathrm{CrN}$ preferential orientation becomes weaker and broader. However (410), (421) and (611) $\mathrm{Cr}_{7} \mathrm{C}_{3}$, (511), (112) and (200) $\mathrm{Cr}_{2} \mathrm{~N}$ preferential orientations become stronger with minor (420) $\mathrm{Cr}_{23} \mathrm{C}_{6}$ peaks (cubic structure, JCPDS 035 0694). Every time the annealing temperature rises, we stimulate the migration of a greater amount of carbon atoms to the film, which leads to the observed increase of the (410) $\mathrm{Cr}_{7} \mathrm{C}_{3}$ peak intensity. This carbide is the most stable and the hardest among all the other carbide phases, especially when it is used as a coating for high carbon steel $[6,17,20]$. From Fig. 4, we can also see a gradual disappearance of $\mathrm{Cr}_{2} \mathrm{~N}$ peaks by the reaction of chromium coating with XC100 substrate. This is due to the difference in crystal structures of carbon, chromium carbide and chromium nitride. The carbon atoms can easily replace the nitrogen atoms in the chromium nitride crystal structure to form chromium carbide [21-24]. Thus, the carbon element perturbs the normal crystal arrangement of chromium nitrides. In addition, they transform into chromium carbonitride by the appearance of (111) and (131) $\mathrm{Cr}_{3} \mathrm{~N}_{0.6} \mathrm{C}_{0.4}$ at $41.02^{\circ}$ and $51.20^{\circ}$, respectively (cubic structure, JCPDS 01 0892540) [25-28]. This agrees well with earlier works, where carbides and carbonitrides have been successfully formed from transition-metal-nitride-based thin films deposited on high carbon steel $[17,21]$. XRD analysis reveals that the $\mathrm{Cr}_{2} \mathrm{~N}$ phase is thermally stable at $1000{ }^{\circ} \mathrm{C}$ which can be attributed to the presence of sufficient chromium and nitrogen in the deposited coating. This allowed the creation of more stable positions and to consequently facilitate the stability of nitrogen in chromium which was justified with a high N/Cr ratio (0.38) at $1000{ }^{\circ} \mathrm{C}$ (Fig. 2). If we consider the formation energy of 


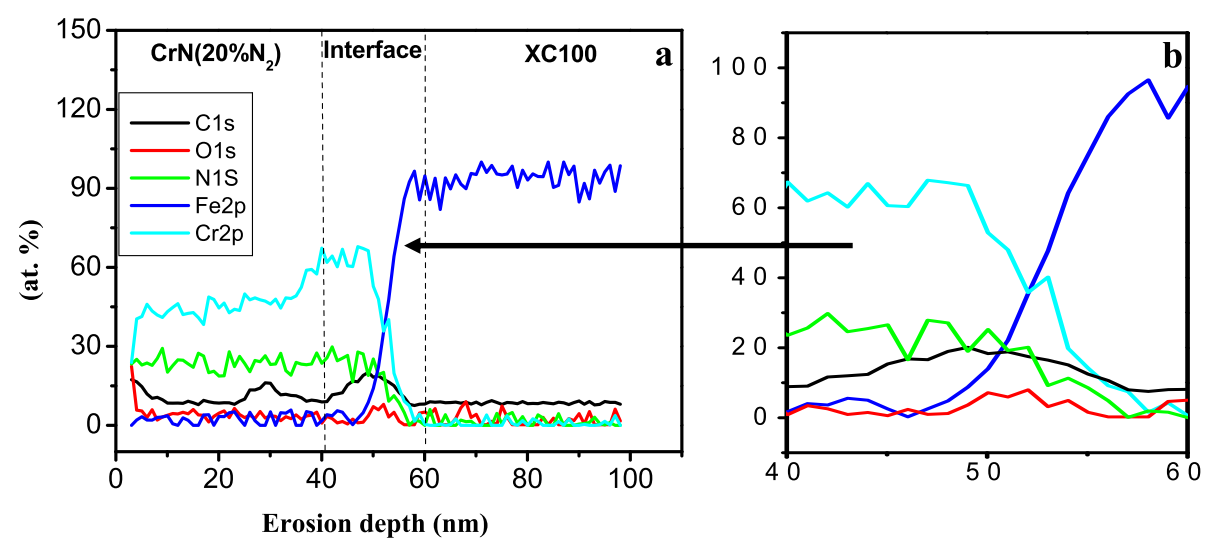

Fig. 3. XPS profiles of $\mathrm{Cr}-\mathrm{N} / \mathrm{XC} 100$ sample annealed at $900{ }^{\circ} \mathrm{C}$.

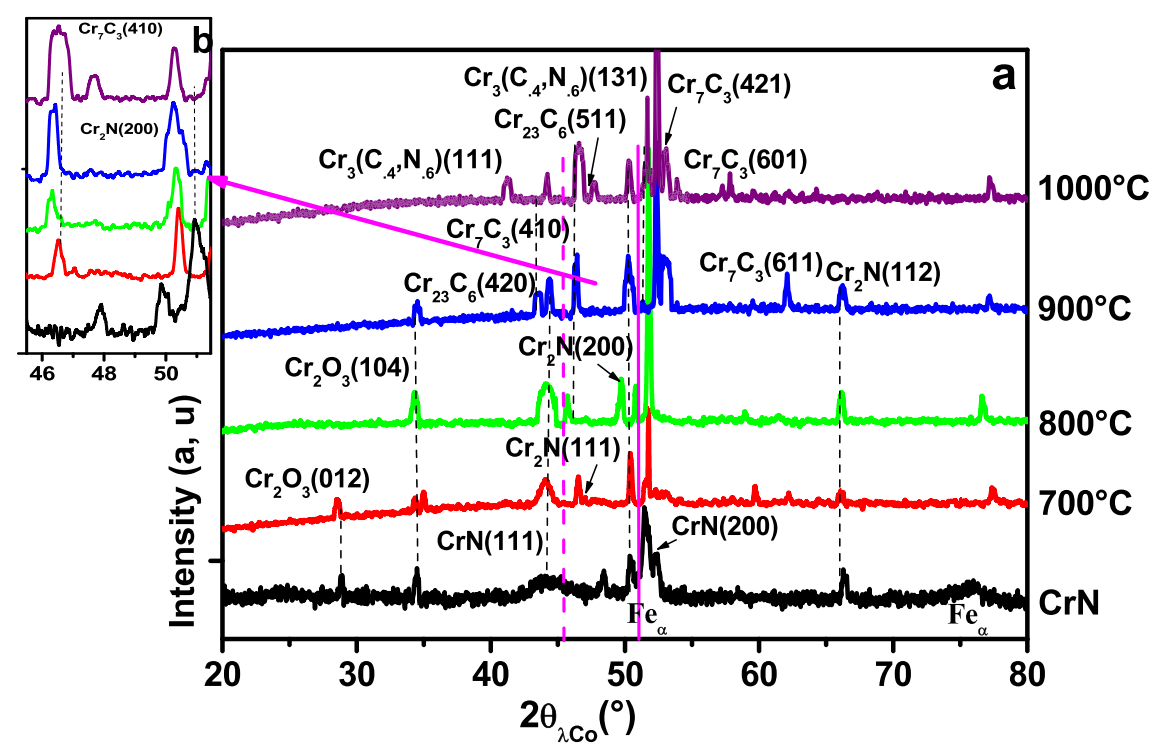

Fig. 4. XRD patterns of $\mathrm{CrN} / \mathrm{XC100}$ samples for different annealing temperatures.

these compounds, the $\mathrm{Cr}_{2} \mathrm{~N}$ can be formed in the interval of 7-10 at.\% $\mathrm{N}_{2}$ at $650{ }^{\circ} \mathrm{C}$ and requires formation energy of about $397.4 \pm 0.4 \mathrm{eV}$ $[12,16,18]$. This value is higher than that of $\mathrm{CrN}$ phase which is formed at higher nitrogen concentration ( $>15 \% \mathrm{~N}_{2}$ in the gas mixture) at $750{ }^{\circ} \mathrm{C}$ and needs formation energy of about $396.8 \pm 0.4 \mathrm{eV}$ [16]. Thus, on one hand, the formation of different phases of chromium nitrides can be justified and attributed to the nitrogen percentage. On the other hand, the transformation of chromium nitrides to chromium carbonitrides in the coatings from $900{ }^{\circ} \mathrm{C}$ consolidates the properties of carbides and nitrides, which can be explained by the smallest carbon atomic radius among the other elements $(\mathrm{Cr}, \mathrm{Fe}$, and $\mathrm{N})$. Moreover, the activation energy for carbon diffusion in polycrystalline chromium is $1.14 \mathrm{eV}$ and that of carbon into iron is about $1.4 \mathrm{eV}[6,22]$. These values are less than the activation energy of nitrogen into chromium. So, the carbon can be diffused and stabilized in chromium more easily than nitrogen. Consequently, annealing treatment facilitates the rearrangement of chromium, carbon and nitrogen to give different compounds. Nouveau et al. [18] and Warcholinski et al. [23] have confirmed the formation of chromium nitrides and carbonitrides. At $900{ }^{\circ} \mathrm{C}$, the existence of oxygen shows the presence of (104) $\mathrm{Cr}_{2} \mathrm{O}_{3}$ oxide at $34.2^{\circ}$ (hexagonal structure, JCPDS 85-0869), with a minor intensity diffraction peak. Many studies confirm that the presence of chromium oxide is still observed in based-chromium films deposited by PVD processes at high vacuum [12] and even after their annealing under vacuum [6].

The annealing treatment favourises the diffusion of carbon in the
CrN coatings, which confirms the formation of binary hard chromium carbide. However, the chemical and structural characterization doesn't exhibit the incorporation of the Fe atoms in the $\mathrm{CrN}$ lattice. Indeed, the diffusion activation energy of $\mathrm{Fe}$ into polycrystalline $\mathrm{Cr}(3.45 \mathrm{eV})$ is higher than the diffusion energy of $\mathrm{C}$ into polycrystalline $\mathrm{Cr}(1.15 \mathrm{eV})$. This justifies the fact that the diffusion of $\mathrm{C}$ has preceded the diffusion of Fe from the substrate towards the CrN coatings [6].

$\mathrm{XRD}$ analysis reveals that the shift in the peak positions towards lower $2 \theta$ angles as annealing temperature increases is proportional to an increase in the lattice parameter $a$. The $\mathrm{Cr}_{7} \mathrm{C}_{3}$ (410) reflection is broadened and becomes increasingly asymmetric while the $\mathrm{Cr}_{2} \mathrm{~N}(200)$ slightly decreases with increasing both annealing temperature and $\mathrm{C}$ content as shown in Figs. 4 and 5: (200) $\mathrm{Cr}_{2} \mathrm{~N}$ located at 50.29 (at $800{ }^{\circ} \mathrm{C}$ ), $50.40^{\circ}$ (at $900^{\circ} \mathrm{C}$ ) and $50.52^{\circ}$ (at $1000^{\circ} \mathrm{C}$ ), and $(410) \mathrm{Cr}_{7} \mathrm{C}_{3}$ located at $46.01^{\circ}$ (at $800^{\circ} \mathrm{C}$ ); $46.64^{\circ}$ (at $900^{\circ} \mathrm{C}$ ) et $46.547^{\circ}$ (at $1000^{\circ} \mathrm{C}$ ), respectively. Further heating of the sample provides additional energy helping the carbon atoms to displace which leads to a reduction in the peak width as the coating composition becomes more homogeneous. The presence of further narrow peaks suggests the main effect of heat treatment and the significant variation in the chemical composition of coatings. This result is strongly supported and confirmed with the composition measurements described in Section 3.1.1 (Fig. 1).

The inter-reticular distance $\mathrm{d}_{(200)}$ of $\mathrm{Cr}_{2} \mathrm{~N}$ decreases progressively in contrary to the increase of $\mathrm{d}_{(410)}$ of $\mathrm{Cr}_{7} \mathrm{C}_{3}$ during the annealing treatment with the replacement of nitrogen by smaller carbon atoms within 


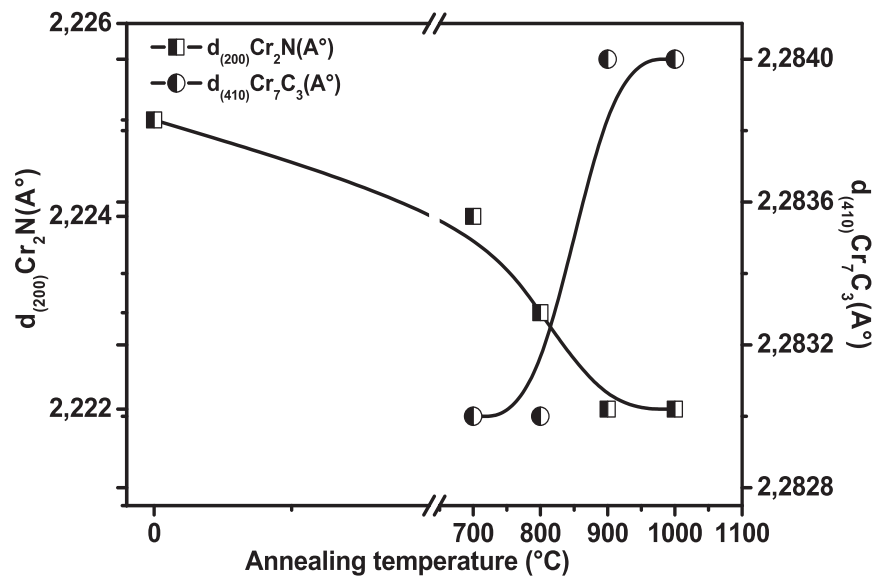

Fig. 5. Inter-reticular distance of $\mathrm{Cr}_{2} \mathrm{~N}(200)$ and $\mathrm{Cr}_{7} \mathrm{C}_{3}$ (410) as a function of annealing temperature.

the mixed chromium carbonitride solid solution and the formation of chromium carbides (Fig. 5). This tendency is consistent with the lattice parameter $(a)$ of both binary nitride $\left(\mathrm{Cr}_{2} \mathrm{~N}: a=4.78 \AA\right.$ ) and carbide $\left(\mathrm{Cr}_{7} \mathrm{C}_{3}: a=7.014 \AA\right.$ ) assuming stoichiometric compositions. As each binary compound ( $\mathrm{Cr}-\mathrm{N}, \mathrm{Cr}-\mathrm{C}$ ) is reported as fully mutually soluble, it should be possible to interpolate between the lattice parameters of the chromium nitride and carbide and derive the lattice parameter of the chromium carbonitride $\mathrm{Cr}_{3} \mathrm{C}_{0.4} \mathrm{~N}_{0.6}(a=4.81 \AA)$. Recent studies of carbonitride $\mathrm{Me}(\mathrm{C}, \mathrm{N})$ phases produced by high-energy ball milling are in line with these observations [24]. This is explained by the increase of microstructural strain or crystallite size effects in the film [17].

The changes in the bonding structure of $\mathrm{Cr}-\mathrm{N}$ coatings were analysed. The C1s, Cr2p $(1 / 2,3 / 2)$ and N1s spectra in the XPS analysis of Cr$\mathrm{N}$ coatings were detected (Fig. 6). At $900^{\circ} \mathrm{C}$, the Cr2p XPS spectra (Fig. 6.a) can be decomposed with different binding energies of 574.23 eV (Cr-C), 575.46 eV (Cr-N), 576.50 eV (Cr-N), 583.63 eV (Cr-C) and $585.34 \mathrm{eV}$ (Cr-O), which correspond to $\mathrm{Cr}_{7} \mathrm{C}_{3}, \mathrm{CrN}_{2} \mathrm{Cr}_{2} \mathrm{~N}, \mathrm{Cr}_{7} \mathrm{C}_{3}$ and $\mathrm{Cr}_{2} \mathrm{O}_{3}$, respectively $[6,12]$. Fig. 6.b illustrates the N1s spectra fitting curves of Cr-N coating, where the N1s peak is decomposed into two peaks with binding energies of $396.84 \mathrm{eV}$ and $397.89 \mathrm{eV}$, which correspond to $\mathrm{Cr}-\mathrm{N}$ [12]. This gives additional evidence to support the bonding of $\mathrm{N}$ to $\mathrm{Cr}$ after annealing treatment at $900{ }^{\circ} \mathrm{C}$ and it is maybe due to the higher electronegativity of nitrogen [25]. These results mean that $\mathrm{CrN}$ and $\mathrm{Cr}_{2} \mathrm{~N}$ coexist in the sample as shown from the XRD analysis (Fig. 4) [26,27]. As shown in Fig. 6.c, the C1s peak, can be fitted into two peaks, which centre on $282.98 \mathrm{eV}$ and $284.34 \mathrm{eV}$ corresponding to C-Cr and sp ${ }^{2} \mathrm{C}-\mathrm{C}$, respectively presenting the $\mathrm{Cr}_{7} \mathrm{C}_{3}$ and free carbon $[25,28]$. At $1000^{\circ} \mathrm{C}$, we notice a significant decrease in the $\mathrm{Cr} 2 \mathrm{p}$ spectra intensity and changes in the N1s and C1s spectra (Fig. 6.d). The
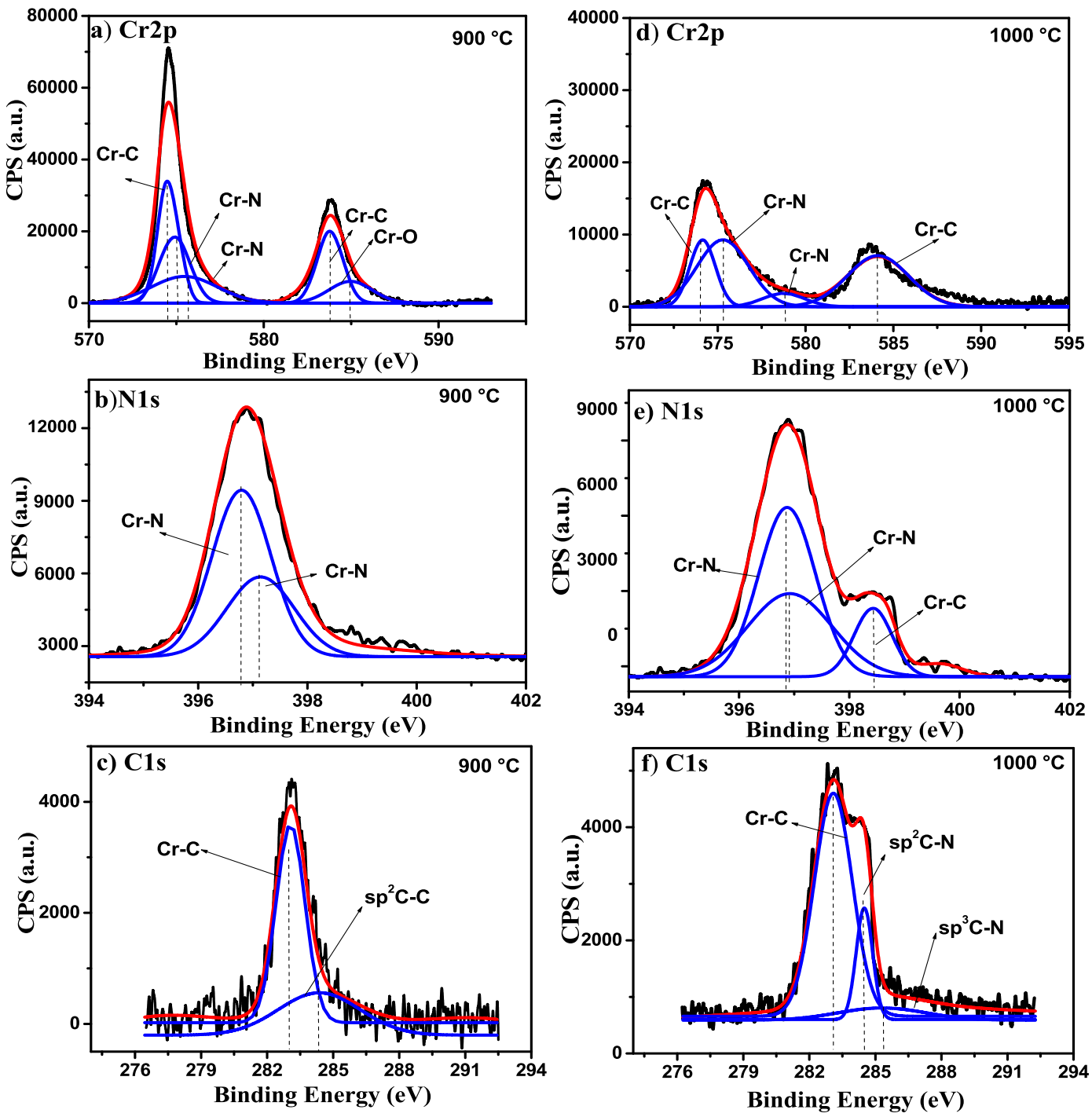

Fig. 6. The fitted Cr2p, N1s and C1s XPS spectra of $\mathrm{Cr}-\mathrm{N}$ coatings annealed at 900 and $1000{ }^{\circ} \mathrm{C}$. 

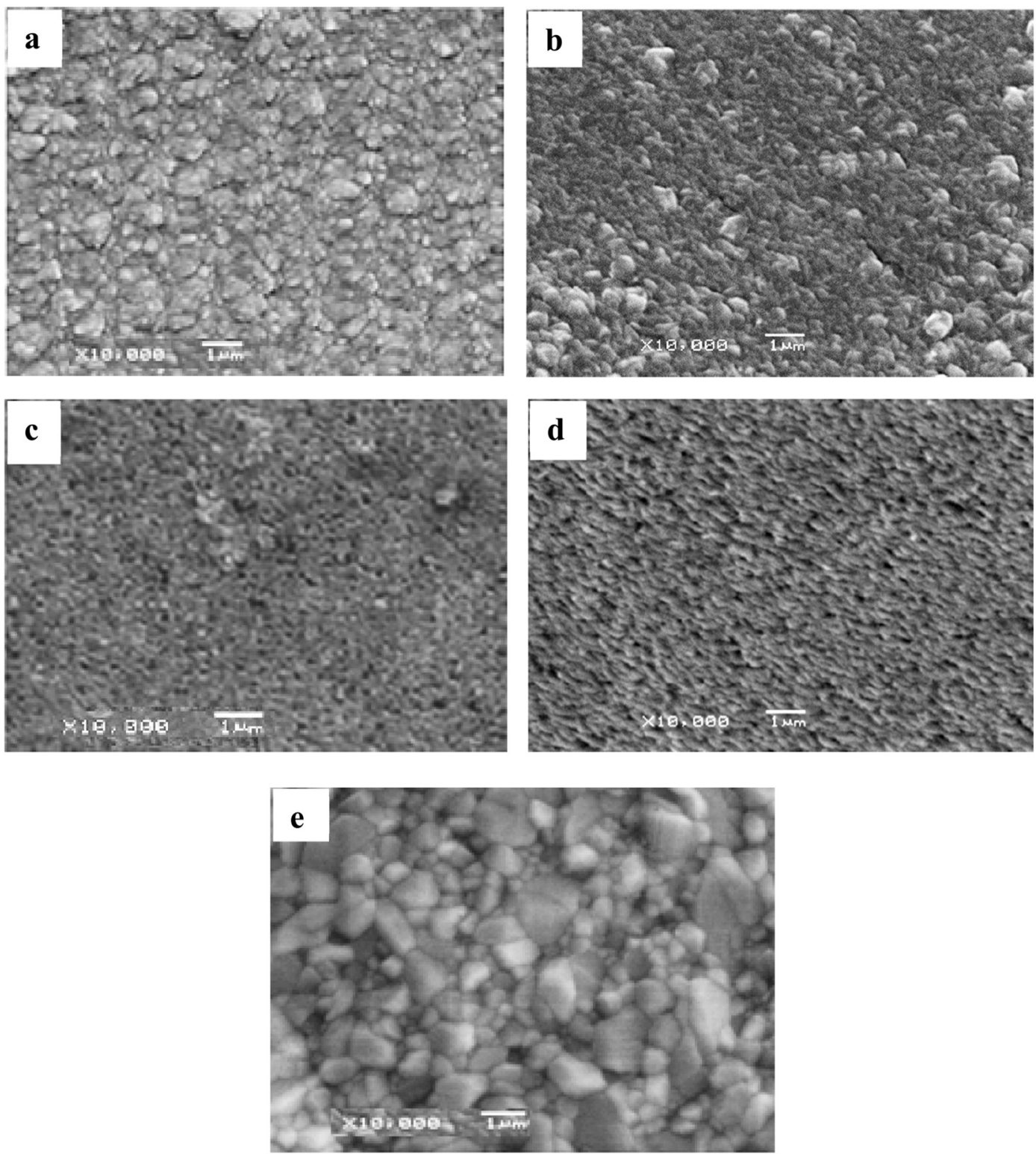

Fig. 7. SEM surface morphology of $\mathrm{Cr}-\mathrm{N} / \mathrm{XC} 100$ samples: a) before and after annealing at: b) $700{ }^{\circ} \mathrm{C}$, c) $800{ }^{\circ} \mathrm{C}$, d) $900{ }^{\circ} \mathrm{C}$ and e) $1000{ }^{\circ} \mathrm{C}$.

Cr2p spectra can be fitted into four components, located at about $574.21 \mathrm{eV}, 575.7 \mathrm{eV}, 576.31 \mathrm{eV}, 583.60 \mathrm{eV}$ and $586.41 \mathrm{eV}$, corresponding to $\mathrm{Cr}_{7} \mathrm{C}_{3}$ and $\mathrm{Cr}_{2} \mathrm{~N}$ [25-28]. For the N1s (Fig. 6.e), the main binding energy at $397.03 \mathrm{eV}$ was decomposed into two overlapping peaks at 396.98 and $397.12 \mathrm{eV}$, corresponding to $\mathrm{N}-\mathrm{Cr}$ bond due to $\mathrm{CrN}$ and $\mathrm{Cr}_{2} \mathrm{~N}$, respectively [25]. However, the minor peak located at $398.62 \mathrm{eV}$ corresponds to $\mathrm{N}-\mathrm{C}$ bond [29]. The main C1s fine spectra (at $1000^{\circ} \mathrm{C}$, Fig. 6.f) is located at a binding energy of $283.12 \mathrm{eV}$ with a shoulder at a lower binding energy positioned at $283.34 \mathrm{eV}$. Through Gaussian fitting analysis, the peaks at $282.97 \mathrm{eV}, 284.50 \mathrm{eV}$ and $285.51 \mathrm{eV}$ correspond to $\mathrm{C}-\mathrm{Cr}$ (1st peak) and $\mathrm{C}-\mathrm{N}$ bonds. According to Ye et al. [30], the $\mathrm{C}-\mathrm{N}$ bond is composed of $\mathrm{sp}^{2} \mathrm{C}-\mathrm{N}$ and $\mathrm{sp}^{3} \mathrm{C}-\mathrm{N}$. This indicates that the $\mathrm{C}-\mathrm{N}$ binding is strongly formed in the $\mathrm{Cr}-\mathrm{N}$ coatings after incorporation of carbon atoms and confirms the coexistence of chromium nitride, carbide and carbonitride phases in the $\mathrm{Cr}-\mathrm{N}$ system at high annealing temperature as shown with XRD analysis. It is noteworthy that the N1s peak has a higher intensity than that of the C1s peak. This difference probably means that nitrogen is rather less linked to chromium during the transformation of chromium nitrides to chromium carbonitrides by the diffusion of carbon into the $\mathrm{Cr}-\mathrm{N}$ film during annealing. This can be explained by the lattice size effect $\left(\mathrm{r}_{\mathrm{C}}<\mathrm{r}_{\mathrm{N}}\right)$, which facilitates the preferential diffusion of $\mathrm{C}$ in $\mathrm{Cr}$ as compared to N. Also, the standard enthalpies of $\mathrm{Cr}_{7} \mathrm{C}_{3}$ and $\mathrm{CrN}$ formation are respectively 3.47 and $1.14 \mathrm{eV}$ [22], indicating that the $\mathrm{Cr}-\mathrm{C}$ bond is stronger than the $\mathrm{Cr}-\mathrm{N}$ one.

\subsubsection{Films' morphology}

The surface of the $\mathrm{Cr}-\mathrm{N}$ films shows a reflective metallic grey colour with the microstructure characterized by fine crystallite in dome form $(D=13 \mathrm{~nm})$. The surface morphology shows the atom agglomeration during the growth of films (Fig. 7). The cross section SEM images, presented in Fig. 8, show the existence of a columnar structure with good adherence in the interfacial $\mathrm{Cr}-\mathrm{N} / \mathrm{XC100}$ zone due to the low deposition temperature (Fig. 7.a). This structure is typical to the transition zone (T) according to Thornton's model [31]. In our previous work [12], this structure was observed for the $\mathrm{Cr}-\mathrm{N}$ films deposited by the same process. Between 800 and $900{ }^{\circ} \mathrm{C}$ (Fig. 7.c, d), the film surface becomes porous with nodular grains $(\mathrm{D}=18 \mathrm{~nm})$. After annealing at $1000^{\circ} \mathrm{C}$, the SEM images present large and rounded grains $(\mathrm{D}=34 \mathrm{~nm})$ with the appearance of black holes within these grains (Fig. 7.e). The 

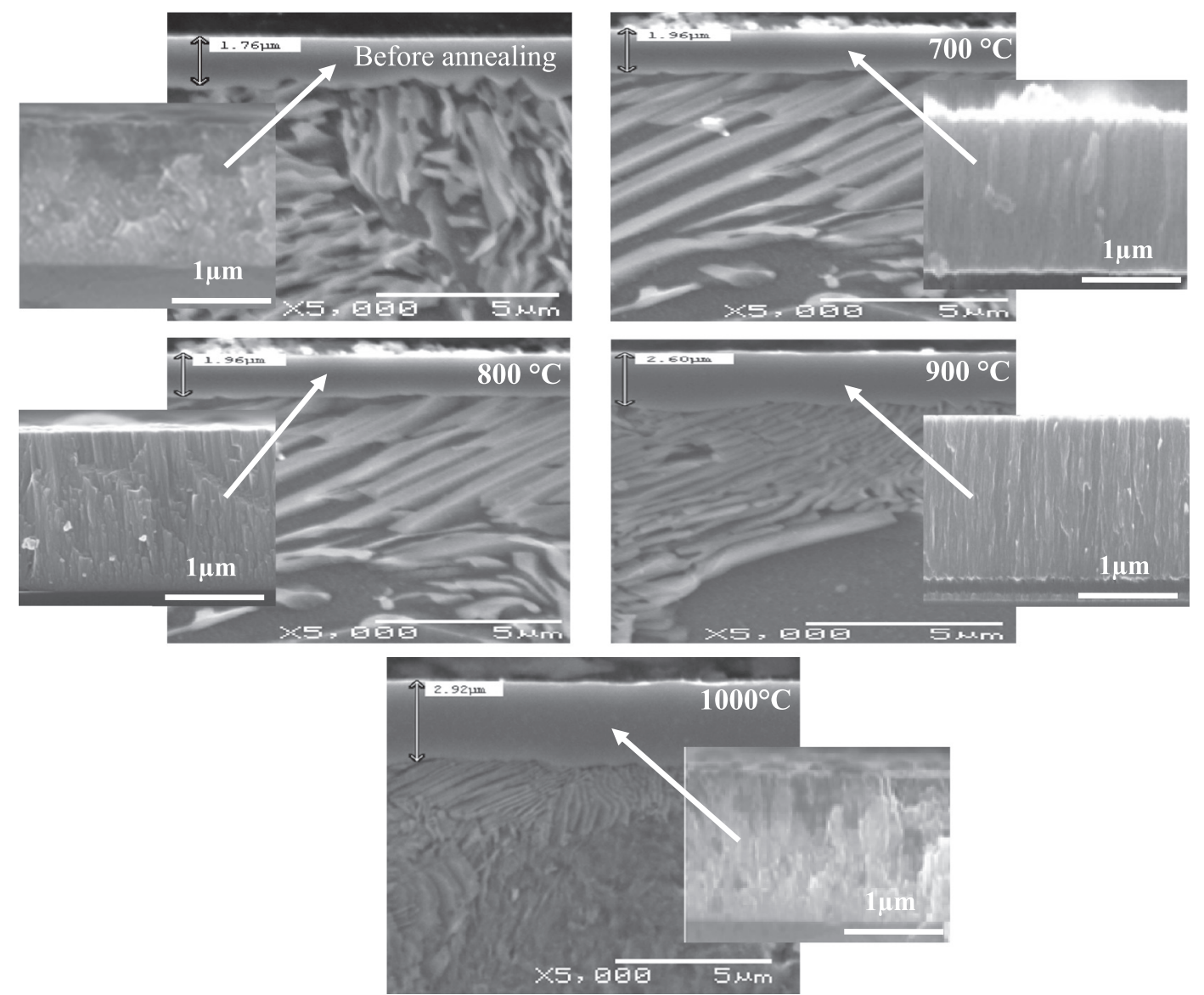

Fig. 8. Cross section SEM morphology of Cr-N/XC100 samples: a) before and after annealing at: b) $700{ }^{\circ} \mathrm{C}$, c) $800{ }^{\circ} \mathrm{C}$, d) $900{ }^{\circ} \mathrm{C}$ and e) $1000{ }^{\circ} \mathrm{C}$.

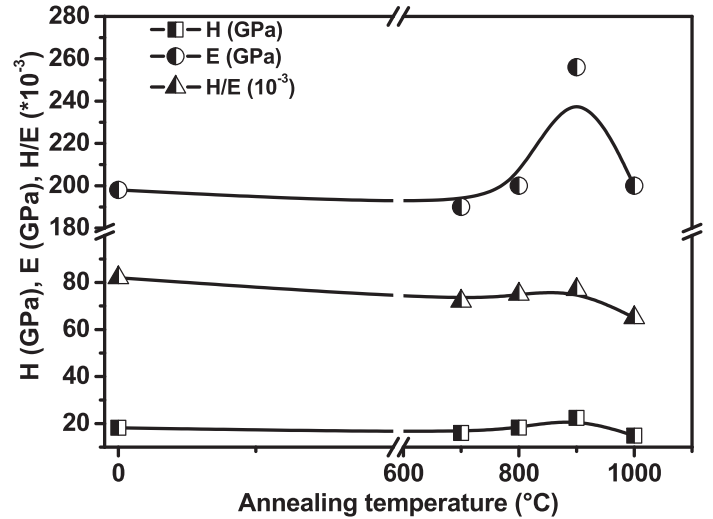

Fig. 9. Hardness, Young's modulus and $\mathrm{H} / \mathrm{E}$ ratio of $\mathrm{Cr}-\mathrm{N}$ coatings for different annealing temperatures.

presence of these holes can be explained by the diffusion of $\mathrm{Cr}$ and $\mathrm{N}$ elements towards the substrate. This structure is characteristic of the transition zone (T) according to Thornton's model [31].

In order to demonstrate the influence of temperature on the film thickness and consequently confirm the diffusion mechanism, different measurements of thickness were performed by using a Scanning Electron Microscope (SEM). It was observed that the film thickness and the surface roughness increased during the annealing treatment: $\mathrm{e}=2.60 \mu \mathrm{m}, \quad \mathrm{Ra}=11 \mathrm{~nm}$ at $800^{\circ} \mathrm{C}$ (Fig. 8.c) and $\mathrm{e}=2.92 \mu \mathrm{m}$, $\mathrm{Ra}=57 \mathrm{~nm}$ at $1000^{\circ} \mathrm{C}$ (Fig. 8.e). Moreover, we did not observe any cracks through the film thickness after annealing treatment at different temperatures suggesting that a high concentration of grain boundaries contributes to the relaxation of stresses in films and prevents the

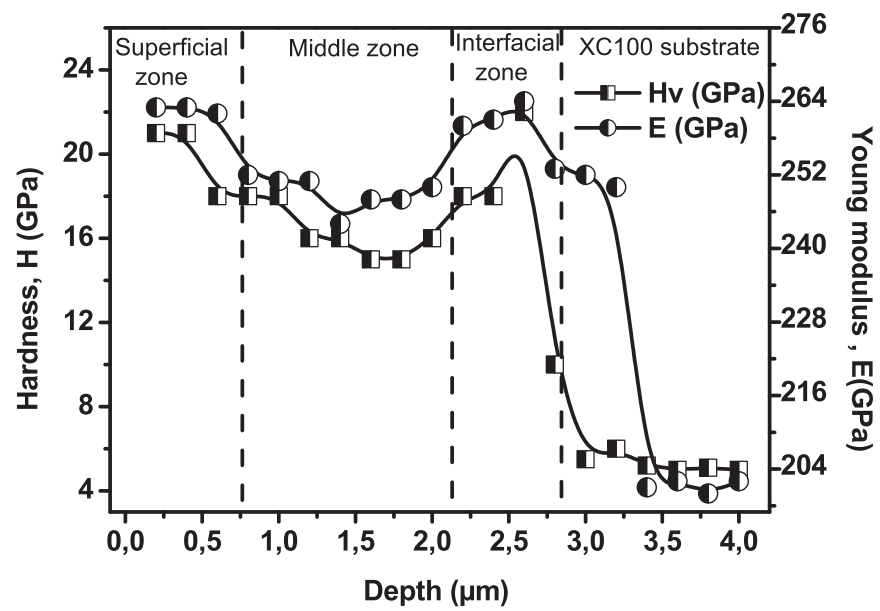

Fig. 10. Hardness and Young's modulus of the $\mathrm{CrN}$ coatings, annealed at $900^{\circ} \mathrm{C}$, as a function of the penetration depth.

propagation of cracks [17].

The coating thickness increased significantly and the interface zone enlarged with the increase in annealing temperature, confirmed by the diffusion of carbon atoms from the substrate to the $\mathrm{CrN}$ film which is thermally activated. At the same time, chromium and nitrogen signal intensity decreased while annealing temperature increased, which suggests a reaction with the carbon to form carbide and carbonitride. Another reason promoting the increase of film thickness is the film microstructure composed of fine columnar grains elongated perpendicularly to the film surface. This corresponds with other work, where 


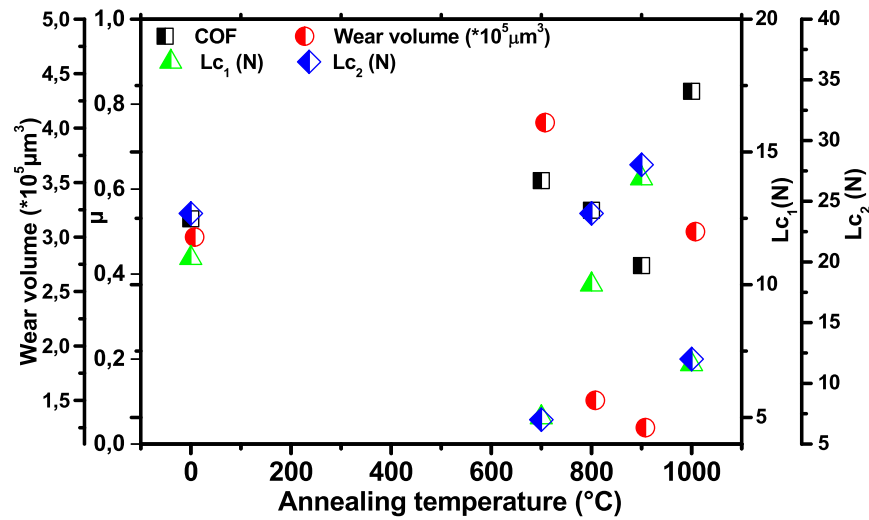

Fig. 11. Friction coefficient, critical loads $\left(\mathrm{Lc}_{1}, \mathrm{Lc}_{2}\right)$ and wear volume of $\mathrm{Cr}-\mathrm{N}$ coatings for different annealing temperatures.

Table 1

Mechanical and tribological properties of $\mathrm{Cr}-\mathrm{C}-\mathrm{N}$ coatings.

\begin{tabular}{|c|c|c|c|c|c|c|c|}
\hline \multirow[t]{2}{*}{ Temperature, ${ }^{\circ} \mathrm{C}$} & \multicolumn{3}{|c|}{ Mechanical properties } & \multicolumn{4}{|c|}{ Tribological properties } \\
\hline & $\mathrm{H}, \mathrm{GPa}$ & $\mathrm{E}, \mathrm{GPa}$ & $\mathrm{H} / \mathrm{E}$ & $\mathrm{CoF}$ & $\begin{array}{l}W_{\mathrm{v}}\left(\times 10^{5}\right) \\
\mu \mathrm{m}^{3}\end{array}$ & $\mathrm{Lc}_{1}$ & $\mathrm{Lc}_{2}$ \\
\hline Before annealing & 18.22 & 198 & 0.092 & 0.53 & 3.00 & 11 & 24 \\
\hline 700 & 16.00 & 190 & 0.084 & 0.62 & 4.05 & 5 & 7 \\
\hline 800 & 18.26 & 200 & 0.091 & 0.55 & 1.50 & 10 & 24 \\
\hline 900 & 22.39 & 256 & 0.087 & 0.42 & 1.25 & 14 & 28 \\
\hline 1000 & 14.86 & 200 & 0.074 & 0.83 & 3.05 & 7 & 12 \\
\hline
\end{tabular}

film thicknesses of zirconium carbide coatings have been greatly increased by raising annealing temperatures [17].

During annealing treatment, the structure of steel substrates was changed from ferrite to lamellar austenite (phase transformation in XC100 steel). The annealing of the hyper-eutectoid XC100 steel (containing $1.17 \mathrm{wt} \%$ of C) up to $800{ }^{\circ} \mathrm{C}$ transforms the eutectoid, the ferrite and the cementite to austenite, which would lead to the dissolution of more carbon and promote the formation of chromium carbides and carbonitrides [17].

\subsection{Mechanical properties of films: hardness $(H)$ and Young's modulus (E)}

\subsubsection{Surface properties}

Fig. 9 presents the hardness $(\mathrm{H})$ and Young's modulus (E) of $\mathrm{Cr}-\mathrm{N}$ films annealed at different temperatures. The curves of both $\mathrm{H}$ and $\mathrm{E}$ show the same tendency. For untreated $\mathrm{Cr}-\mathrm{N}$ film, the hardness and Young's modulus are 18.2 and $198 \mathrm{GPa}$, respectively. These values are close to that obtained by Ibrahim et al. [4] for CrN coatings deposited by magnetron sputtering. However, the film hardness is a little bit lower than that reported in the literature (19-24 GPa) [12,32,33]. This may be attributed to the heat produced by high energetic ion bombardment [33]. A gradual increase in the coating hardness and Young's modulus with an increase in the annealing temperature from 800 to $900{ }^{\circ} \mathrm{C}$ was observed (Fig. 9). The $\mathrm{Cr}-\mathrm{N}$ coatings hardness increased from 18.3 to $22.4 \mathrm{GPa}$ after annealing temperatures of 800 and $900{ }^{\circ} \mathrm{C}$, respectively. This enhancement can be attributed to several factors: the grain size refinement according to Hall-Petch [34], the grouping of defects at the film-substrate interface and the formation of the hardest chromium carbide $\mathrm{Cr}_{7} \mathrm{C}_{3}$ compound in the film with the chromium nitrides. All these parameters will probably contribute to the film hardness increase [22]. However, we observed a decrease in the hardness value from $22.4 \mathrm{GPa}$ at $900{ }^{\circ} \mathrm{C}$ to $14.9 \mathrm{GPa}$ at $1000^{\circ} \mathrm{C}$. This drop can be explained by the interaction between carbon, nitrogen and chromium atoms forming the chromium carbonitrides. In addition, the increase in grain size and the appearance of black holes, which decrease coating density and release the compressive stress in the coatings, can reduce coating resistance to the indenter penetration and decrease hardness. This result was also similarly confirmed by the formation of vanadium carbonitrides films deposited on steel tools by thermal diffusion processes [35]. Furthermore, the maximum measured hardness $(22.4 \mathrm{GPa})$ is low compared to the values reported in the literature for $\mathrm{Cr}-\mathrm{C}-\mathrm{N}$ films deposited by different PVD techniques, which range between 25 and $32 \mathrm{GPa}[30,36]$. Firstly, this can be explained by the under-stoichiometry of $\mathrm{Cr}_{7} \mathrm{C}_{3}$ phase $\left(\mathrm{C} / \mathrm{Cr}=0.4\right.$, at $\left.900{ }^{\circ} \mathrm{C}\right)$ [37]. Secondly, this low value can be related to the oxygen contamination of film. The hardness of chromium oxide is lower than the carbide or nitride and the oxygen incorporation in the $\mathrm{CrN}$ crystal lattice would weaken the covalent $\mathrm{C}-\mathrm{C}$ and $\mathrm{C}-\mathrm{N}$ bonding. The favourable bindings of ionic $\mathrm{Cr}-\mathrm{O}$ lead to a decrease in the mechanical behaviour law [17].

Considering the Young's modulus (Fig. 9) we can clearly see the variation of $\mathrm{E}$ as a function of annealing temperatures. The Young's modulus decreased slightly from $198 \mathrm{GPa}$ before annealing to $192 \mathrm{GPa}$ at $700{ }^{\circ} \mathrm{C}$ with more oxygen contamination (12 at.\%). Schalk et al. [38] also reported a decrease of Young's modulus with an increasing oxygen concentration for sputter-deposited TiAlON coatings. The further increase of carbon content in film, while increasing the annealing temperature from 800 to $900^{\circ} \mathrm{C}$, led to a significant increase in the Young's modulus and to achieve its maximum value of $264 \mathrm{GPa}$. This is probably due to the amorphous carbon phase coming from the formation of $\mathrm{C}-\mathrm{C}$ bonds [38], which was confirmed by the XPS analysis.

It has been revealed that the aptitude of $\mathrm{CrN}$ films to resist mechanical failure at different annealing temperatures is improved by a high $\mathrm{H} / \mathrm{E}$ ratio [9]. It implies that a longer elastic strain to failure for the $\mathrm{Cr}-\mathrm{C}-\mathrm{N}$ thin films allows the redistribution of the applied load over a large area as a function of annealing temperature (Fig. 9) [7]. Before annealing treatment, the $\mathrm{CrN}$ coatings exhibited a higher $\mathrm{H} / \mathrm{E}$ ratio (0.082) as compared to those of the $\mathrm{Cr}-\mathrm{N}$ coatings after annealing (0.065-0.077). Therefore, this result indicates that the untreated $\mathrm{Cr}-\mathrm{N}$ coatings have a high resistance against abrasive wear, low Young's modulus and higher toughness [9,39].

\subsubsection{Evolution of $H$ and $E$ through the film's thickness}

Fig. 10 shows the hardness and Young's modulus of the $\mathrm{Cr}-\mathrm{N}$ coatings, annealed at $900^{\circ} \mathrm{C}$, as a function of the penetration depth. The $\mathrm{Cr}-\mathrm{N}$ coatings exhibited lower hardness and Young's modulus values in the middle zone than those at the surface or the interface zones (Fig. 10). The $\mathrm{Cr}-\mathrm{N}$ coatings displayed high mechanical properties $(\mathrm{H}=22.32 \mathrm{GPa}, \mathrm{E}=264 \mathrm{GPa})$ and $(\mathrm{H}=21.50 \mathrm{GPa}, \mathrm{E}=253 \mathrm{GPa})$ at the film interface and surface, respectively. According to the XPS analysis (Fig. 3), the replacement of $\mathrm{Cr}-\mathrm{N}$ bonds by harder $\mathrm{Cr}-\mathrm{C}$ and $\mathrm{Cr}-\mathrm{N}-\mathrm{C}$ bonds led to enhance the mechanical properties of the film. Therefore, the formation of chromium carbide adjacent to the chromium nitride hinders dislocation movement and leads to an increase in hardness [17]. The gradual decrease in the coating hardness and Young's modulus in the middle zone can be attributed to the migration of nitrogen to the interface between film and substrate. This migration results in less interstitial elements and leads to the absorption or destruction of defects. Consequently the coating hardness decreases.

\subsection{Tribological behaviour of deposited films}

\subsubsection{Friction coefficient}

After annealing treatment of $\mathrm{Cr}-\mathrm{N} / \mathrm{XC100}$ at different temperatures, the tribological properties of coatings were measured. Fig. 11 and Table 1 show friction coefficient, critical loads and wear volume values of untreated and annealed coatings. The tendency of friction coefficient values is opposite to those of hardness and the Young's modulus. Before annealing, the friction coefficient of the $\mathrm{Cr}-\mathrm{N}$ film was 0.53 [12] and initially increased to 0.62 under heat treatment at $700{ }^{\circ} \mathrm{C}$. This can be due to removal of the superficial oxidative layer formed during the film deposition. The carbon diffusion into the $\mathrm{Cr}-\mathrm{N}$ coating can form a self- 

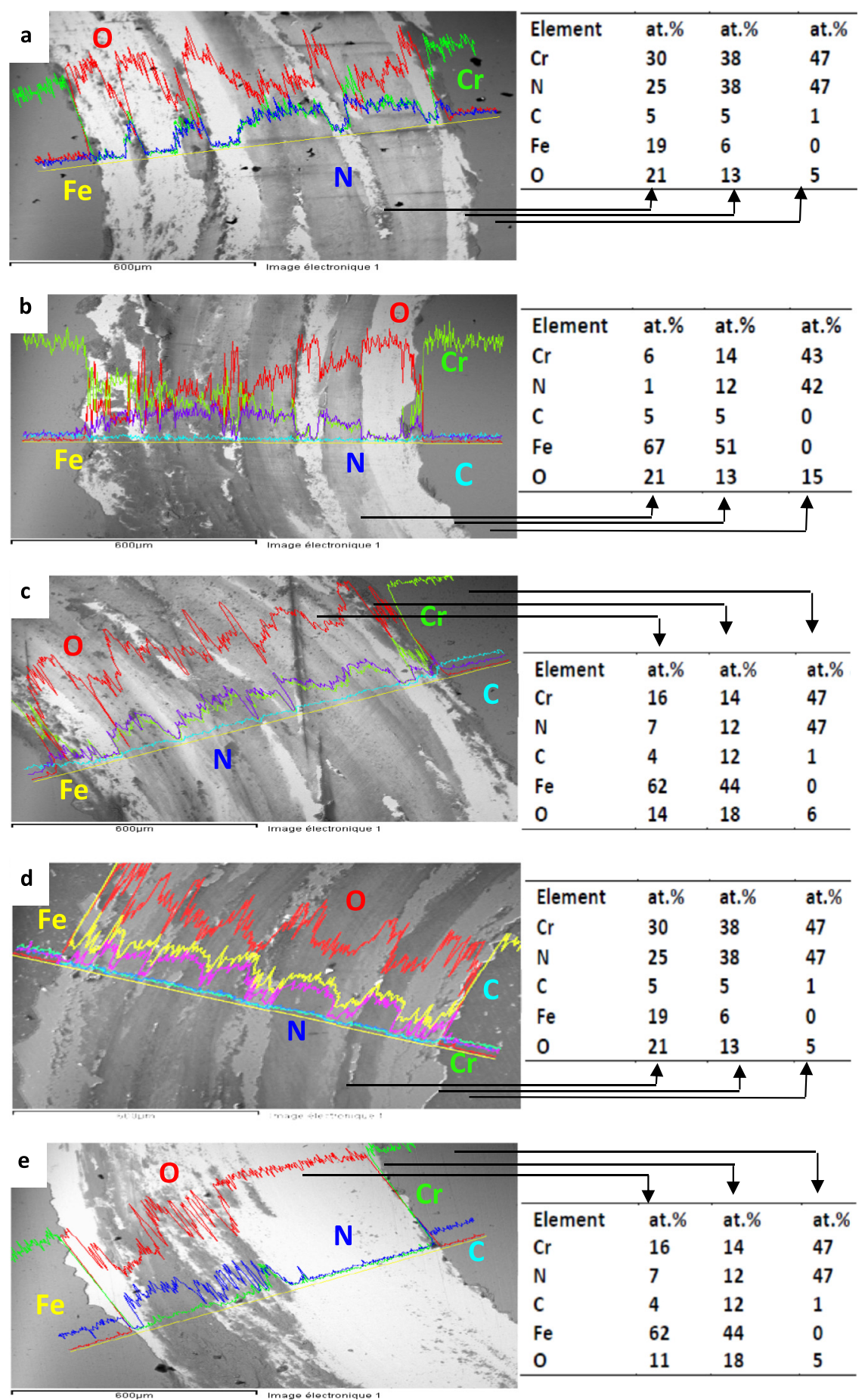

Fig. 12. SEM images and EDS analysis of wear tracks of $\mathrm{Cr}-\mathrm{N} / \mathrm{XC} 100$ : a) before and after annealing at: b) $700{ }^{\circ} \mathrm{C}$, c) $800{ }^{\circ} \mathrm{C}$, d) $900{ }^{\circ} \mathrm{C}$ and e) $1000{ }^{\circ} \mathrm{C}$.

lubricating layer, which can significantly reduce the friction coefficient of $\mathrm{Cr}-\mathrm{C}-\mathrm{N}$ coatings [39]. Increasing the $\mathrm{C}$ content in the $\mathrm{Cr}-\mathrm{N}$ film treated between 800 and $900{ }^{\circ} \mathrm{C}$ led to a decrease in the friction coefficient. Its lowest value of 0.42 was obtained at $900{ }^{\circ} \mathrm{C}$ because of the formation of $\mathrm{Cr}-\mathrm{C}$ bond in the $\mathrm{Cr}_{7} \mathrm{C}_{3}$ compound [7]. However, at $1000^{\circ} \mathrm{C}$, the friction coefficient of the $\mathrm{CrN}$ coating increased to its highest value of 0.86 which can be attributed to the grain coalescence of the $\mathrm{Cr}-\mathrm{N}$ coating favouring the initiation of defects through the film and accelerating the propagation of cracks during sliding [7,39]. In addition, the high surface roughness $\left(\mathrm{Ra}=57 \mathrm{~nm}\right.$ at $\left.1000^{\circ} \mathrm{C}\right)$ reduces the real contact area between the ball and $\mathrm{Cr}-\mathrm{N}$ coating [7]. Although the values of friction coefficient are not very low, this may limit the use of $\mathrm{Cr}-\mathrm{C}-\mathrm{N}$ films in lubricious applications. This result corresponds with previous studies performed on $\mathrm{Cr}-\mathrm{C}-\mathrm{N}$ and $\mathrm{Ti}-\mathrm{C}-\mathrm{N}$ coatings against an alumina ball [29]. The friction coefficient in the tests with a $\mathrm{Cr}-\mathrm{C}-\mathrm{N}$ coating with $2.60 \mu \mathrm{m}$ (at $900{ }^{\circ} \mathrm{C}$ ) was consistently higher than for the thicker coating. It may be attributed to the small grain size, dense structure and defect of the coatings, which is consistent with the result of SEM and roughness. H. Pengfei et al. [7] pointed out that the friction coefficient significantly improved as the grain size decreased.

As shown in Fig. 11, the wear volume has a similar trend to that of the friction coefficient. By increasing the annealing temperature, the wear volume increased from $3 \times 10^{5} \mu^{3}$ (before annealing) to $4.05 \times 10^{5} \mu \mathrm{m}^{3}$ (at $700^{\circ} \mathrm{C}$ ) and then decreased to a minimum value of 
$1.25 \times 10^{5} \mu^{3}$ at $900^{\circ} \mathrm{C}$ with a further diffusion of carbon (10 at.\%), corresponding to the stability of the hard chromium carbide phase. It is noteworthy that the wear volume of the very hard $\mathrm{Cr}-\mathrm{C}-\mathrm{N}$ coatings annealed at $900^{\circ} \mathrm{C}$ is even lower than that of the relatively soft $\mathrm{CrN}$ nitride coating. In general, a lower friction and wear volume with increasing carbon content can be observed, which can be related to the increase of carbon bond fraction which is in agreement with literature [40].

\subsubsection{Adhesion performance}

An oscillating tribometer was used to investigate the adhesion between the $\mathrm{Cr}-\mathrm{N}$ coatings and the XC100 steel substrates. Two critical loads were defined: the cohesive failure critical load $\left(\mathrm{Lc}_{1}\right)$ and the adhesion failure critical load $\left(\mathrm{Lc}_{2}\right)$ (Fig. 11). It is obvious that the critical loads are inversely proportional to that of the friction coefficient.

Good adhesion between coatings and substrate is a main goal for good tribological behaviour [9]. For the $\mathrm{Cr}-\mathrm{N}$ coating (Fig. 12.a), before annealing treatment, the wear track was wide with a critical load of $\mathrm{Lc}_{2}=24 \mathrm{~N}$ (Fig. 11), which makes the coating poorly worn with the appearance of $\mathrm{Cr}$ (30 at.\%) and $\mathrm{N}$ (25 at.\%) in the wear track due to fatigue fracture. This indicates that the friction coefficient between the coating and $100 \mathrm{Cr} 6$ ball is high $(\mu=0.53)$ and suggests that the wear mechanism is generally adhesive together with slight abrasive wear.

At $700{ }^{\circ} \mathrm{C}$ (Fig. 12.b), the coating adhesion was significantly weaker than that of untreated $\mathrm{Cr}-\mathrm{N}$ coating, which was indicated by the severe cracking and large delamination that occurred at a lower load (5 and $7 \mathrm{~N}$ ). Taking into account the existence of chromium nitrides at $700{ }^{\circ} \mathrm{C}$, this may be due to high oxidation of the films (18 at.\% of O). Also, the difference between both the Young's modulus of coating and substrate leads to a higher concentration of shear stresses in the interfacial zone (coating-substrate), which contributes to the increase in wear volume [9].

At $800^{\circ} \mathrm{C}$, the wear rate was slightly higher than that at $900{ }^{\circ} \mathrm{C}$ with a critical load of $\mathrm{L}_{\mathrm{c} 1}=14 \mathrm{~N}$ (Figs. 11 and 12.c). This could be due to a more pronounced oxidation rate $(\mathrm{O}=13$ at.\%) as shown by XRD analysis (Fig. 4).

At $900{ }^{\circ} \mathrm{C}$ (Fig. 12.d), the wear track became narrower and the debris on the wear track was in small amounts. The $\mathrm{Cr}-\mathrm{C}-\mathrm{N}$ coating presented a medium adhesive $\left(\mathrm{Lc}_{1}=14 \mathrm{~N}\right)$ and cohesive $\left(\mathrm{Lc}_{2}=28 \mathrm{~N}\right)$ critical loads. The EDS analysis of the wear track region showed that the chemical composition of the wear debris was 38 at.\% Cr, 38 at.\% N, 13 at.\% $\mathrm{O}, 6$ at.\% $\mathrm{Fe}$ and 5 at.\% C. This indicates that the adhesion decreased gradually with an increasing annealing temperature and abrasive wear. Fig. 11 shows the decrease in the wear volume with an increase in annealing temperature achieving its lowest value of $1.25 \times 10^{5} \mu \mathrm{m}^{3}$ at $900{ }^{\circ} \mathrm{C}$ then increased to $3.05 \times 10^{5} \mu \mathrm{m}^{3}$ at $1000^{\circ} \mathrm{C}$. These may be attributed to higher hardness values, grain size refinement and the formation of stronger $\mathrm{C}-\mathrm{C}$ and $\mathrm{C}-\mathrm{N}$ bonds. Also, good adhesion and a significant reduction of the friction coefficient depicted strong interfacial bonding between the film and the substrate, as observed during scratch testing of our coatings [41].

After annealing treatment at $1000{ }^{\circ} \mathrm{C}$ (Fig. 12.e), superficial chipping was observed at the edge of the scratch track which appears to be in the initial stage for the adhesive failure of chromium nitride film at $\mathrm{Lc}_{2}=12 \mathrm{~N}$. This may be due to the low concentrations of $\mathrm{Cr}$ (14 at.\%) and N (12 at.\%) compared to those of Fe (44 at.\%) and C (12 at.\%) in the analysed scratch track. This can also be correlated with the poor adhesion and deformation of the films as observed during the scratch test. It can be concluded that the deposited coatings exhibited better mechanical and tribological properties at $900^{\circ} \mathrm{C}$. Furthermore, the presence of a high quantity of oxygen (15-20 at.\%) in the wear track compared to those in the pure $\mathrm{CrN}$ coatings contributes to high wear rate at room temperature in ambient air.

\section{Conclusion}

The effects of annealing on $\mathrm{Cr}-\mathrm{N}$ magnetron sputtered XC100 samples were investigated on the structure, morphology, mechanical and tribological properties of the coatings.

The stability of chromium nitrides deposited on XC100 samples was achieved between 700 and $800{ }^{\circ} \mathrm{C}$. The formation of $\mathrm{Cr}_{7} \mathrm{C}_{3}$ carbide was observed which is due to the diffusion of carbon atoms from steel substrate towards the deposited film from $800{ }^{\circ} \mathrm{C}$. However, the $\mathrm{Cr}_{23} \mathrm{C}_{6}$ carbide only appeared at $\mathrm{T} \geq 900^{\circ} \mathrm{C}$.

The diffusion of $\mathrm{Cr}$ and $\mathrm{N}$ led to partial transformation of the chromium nitrides to chromium carbonitrides $\mathrm{Cr}_{3} \mathrm{~N}_{0.6} \mathrm{C}_{0.4}$ at $1000{ }^{\circ} \mathrm{C}$.

The best mechanical properties of the $\mathrm{Cr}-\mathrm{N}$ films were obtained at $900{ }^{\circ} \mathrm{C}$ with the formation of a chromium carbide and nitride mixture. Hardness and Young's modulus of films gradually decreased with the transformation of chromium nitrides to carbonitrides.

The best wear resistance and coefficient of friction in $\mathrm{Cr}-\mathrm{C}-\mathrm{N}$ coatings were observed at $900{ }^{\circ} \mathrm{C}$ and were $1.25 \times 10^{-5} \mu \mathrm{m}^{3}$ and 0.42 , respectively. However, it is noteworthy that annealing at 700 and $1000{ }^{\circ} \mathrm{C}$ led to the formation of pores and oxides and, as a consequence, to the damage and total delamination of all the $\mathrm{Cr}-\mathrm{N}$ films.

\section{References}

[1] H.N. Shah, R. Jayaganthan, D. Kaur, R. Chandra, Influence of sputtering parameters and nitrogen on the microstructure of chromium nitride thin films deposited on steel substrate by direct-current reactive magnetron sputtering, Thin Solid Films 518 (20) (2010) 5762-5768.

[2] S. Lakra, H.-S. Maharana, A. Basu, Synthesis and characterization of $\mathrm{Cr}^{-} \mathrm{ZrO}_{2}$, composite coating formed by DC and pulse electrodeposition, Mater. Manuf. Process. 31 (11) (2016) 1447-1453.

[3] H.S. Akkera, N.N.K. Reddy, M.C. Sekhar, Thickness dependent structural and electrical properties of magnetron sputtered nanostructured $\mathrm{CrN}$ thin films, Mater. Res. 20 (3) (2017) 712-717.

[4] Khalil Ibrahim, M.M. Rahman, X. Zhao, J.-P. Veder, Z.-F. Zhou, E. Mohammadpour, R.H. Majeed, A.-N. Nikoloski, Z.-T. Jiang, Annealing effects on microstructural, optical, and mechanical properties of sputtered CrN thin film coatings: experimental studies and finite element modeling, J. Alloys Compd. 25 (2018) 451-464.

[5] G.G. Fuentes, R. Rodriguez, J.C. Avelar-Batista, J. Housden, F. Montala, L.J. Carreras, A.B. Cristobal, J.J. Damborenea, T.J. Tate, Recent advances in the chromium nitride PVD process for forming and machining surface protection, J. Mater. Process. Technol. 167 (2005) 415-421.

[6] M. Fellah, L. Aissani, A. Zairi, M. Abdul Samad, C. Nouveau, M.Z. Touhami, H. Djebaili, A. Montagne, A. Iost, Thermal treatment effect on structural and mechanical properties of Cr-C coatings, Int. J. Surf. Eng. Coat. 96 (2) (2018) 79-85.

[7] H. Pengfei, J. Bailing, Study on tribological property of CrCN coating based on magnetron sputtering plating technique, Vacuum 85 (11) (2011) 994-998.

[8] B. Xiao, J. Feng, C.T. Zhou, Y.H. Jiang, R. Zhou, Mechanical properties and chemical bonding characteristics of $\mathrm{Cr}_{7} \mathrm{C}_{3}$ type multicomponent carbides, J. Appl. Phys. 109 (2) (2011) 23507.

[9] J. Lin, W.D. Sproul, J.J. Moore, S. Lee, S. Myers, High rate deposition of thick CrN and $\mathrm{Cr}_{2} \mathrm{~N}$ coatings using modulated pulse power (MPP) magnetron sputtering, Surf Coat. Technol. 205 (2011) 3226-3234.

[10] A. Basu, J. Dutta Majumdar, I. Manna, Structure and properties of $\mathrm{Cr}_{\mathrm{x}} \mathrm{N}$ coating, Surf. Eng. 28 (3) (2013) 199-204.

[11] Y. Zou, M.J. Walock, I. Rahil, C. Nouveau, A. Stanishevsky, The effect of composition on the structure, mechanical properties, and thermal stability of sputter coated ternary chromium-molybdenum-nitride coatings, Soc. Vac. 505 (2012) 856-7188.

[12] L. Aissani, C. Nouveau, M.J. Walock, H. Djebaili, A. Djelloul, Influence of vanadium on structure, mechanical and tribological properties of CrN coatings, Surf. Eng. 31 (10) (2015) 779 .

[13] K.H. Kim, E.Y. Choi, S.G. Hong, B.G. Park, J.H. Yoon, J.H. Yong, Syntheses and mechanical properties of Cr-Mo-N coatings by a hybrid coating system, Surf. Coat. Technol. 201 (2006) 4068-4072.

[14] A. Gilewicz, D. Murzynski, E. Dobruchowska, J. Kwiatkowski, R. Olik, J. Ratajski, B. Warcholinski, Wear and corrosion behavior of $\mathrm{CrCN} / \mathrm{CrN}$ coatings deposited by cathodic arc evaporation on nitrided 42CrMo4 steel substrates, Prot. Met. Phys. Chem. Surf. 53 (2) (2017) 312-321.

[15] J. Almer, M. Oden, G. Hakansson, Microstructure and thermal stability of arc evaporated Cr-C-N coatings, Philos. Mag. 84 (7) (2004) 611-630.

[16] M.H. Staia, A. Trocelis, A. Zairi, M. Suarez, E.S. Puchi-Cabrera, A. Iost, A. Montagne, Assessment of the mechanical and tribological performance of a $\mathrm{ZrN}$ PVD coating, Surf. Eng. (2017), https://doi.org/10.1080/02670844.2017.1414766.

[17] K. Benouareth, P. Tristant, C. Jaoul, C. Le Niniven, C. Nouveau, C. D-Tixier, A. Bouabellou, Study of the interaction between a zirconium thin film and a C100 steel substrate: temperature effect, J. Vac. 125 (2016) 234-239.

[18] C. Nouveau, M.A. Djouadi, C. Décès-Petit, The influence of deposition parameters 
on the wear resistance of $\mathrm{Cr}_{x} \mathrm{~N}_{y}$ magnetron sputtering coatings in routing of oriented strand board, Surf. Coat. Technol. 174-175 (2003) 455-460.

[19] O. Knotek, F. Löffler, G. Krämer, R.F. Bunshah, G.E. McGuire, S.M. Rossnagel, Applications to cuttings tools: CVD-coated cutting tools by R.F, Handbook of Hard Coatings: Deposition Technologies, Properties and Applications, 2000, pp. 377-379.

[20] A.M. Neves, V. Severo, L. Cvrcek, T. Polcar, C. Louro, A. Cavaleiro, In situ structural evolution of arc-deposited Cr-based coatings, Surf. Coat. Technol. 202 (22-23) (2008) 5550-5555.

[21] O. Lupicka, B. Warcholinski, The adhesion of $\mathrm{CrN}$ thin films deposited on modified 42CrMo4 steel, Adv. Mater. Sci. Eng. (2017) 4064208, , https://doi.org/10.1155/ 2017/4064208 (14 pages).

[22] R. Gheriani, R. Halimi, R. Bensaha, Effect of substrate surface ion bombardment etching on reaction between chromium thin films and steel substrates, Surf. Coat Technol. 180-181 (2004) 49-52.

[23] B. Warcholinski, A. Gilewicz, Z. Kuklinski, P. Myslinski, Arc-evaporated CrN, CrN and CrCN coatings, Vacuum 83 (2008) 715-718.

[24] A. Vyas, Y.G. Shen, Z.F. Zhou, K.Y. Li, Nano-structured CrN/CNx multilayer films deposited by magnetron sputtering, Compos. Sci. Technol. 68 (2008) 2922-2929.

[25] F. Schuster, F. Maury, J.F. Nowak, Influence of organochromium precursor chem istry on the microstructure of MOCVD chromium carbide coatings, Metallurgical Coatings and Thin Films, 43-44 1990, pp. 185-198.

[26] J. Lin, J.J. Moore, W.C. Moerbe, M. Pinkas, B. Mishra, G.L. Doll, W.D. Sproul, Structure and properties of selected (Cr-Al-N, TiC-C, Cr-B-N) nanostructured tribological coatings, Int. J. Refract. Met. Hard Mater. 28 (1) (2010) 2-14.

[27] L. Aissani, M. Fellah, C. Nouveau, M.A. Samad, A. Montagne, A. Iost, Structural and mechanical properties of $\mathrm{Cr}-\mathrm{Zr}-\mathrm{N}$ coatings with different $\mathrm{Zr}$ content, Surf. Eng. (2017), https://doi.org/10.1080/02670844.2017.1338378.

[28] Y. Ye, Y. Wang, H. Chen, J. Li, Y. Yao, C. Wang, Doping carbon to improve the tribological performance of $\mathrm{CrN}$ coatings in seawater, Tribol. Int. 90 (2015) 362-371.

[29] W. Tillmann, J. Herper, I.-A. Laemmerhirt, Development and tribological investigation of the coating system chromium carbonitride $(\mathrm{CrCN})$ to different surface designs, J. Mater. Sci. Eng. B 2 (4) (2012) 223-229.

[30] Y.W. Ye, Y.X. Wang, H. Chen, L.J. Li, S.G. Zhou, Q.J. Xue, Influences of bias voltage on the microstructures and tribological performances of $\mathrm{Cr}-\mathrm{C}-\mathrm{N}$ coatings in seawater, Surf. Coat. Technol. 270 (2015) 305-313.

[31] J.A. Thornton, High rate thick film growth, Annu. Rev. Mater. Sci. 7 (1977) 239-260.

[32] J.-W. Lee, J.-C. Huang, J.-G. Duh, Nano mechanical properties evaluation of R. F. magnetron sputtered chromium nitride thin film, Tamkang J. Sci. Eng. 7 (4) (2004) 237-240.

[33] A.P. Ehiasarian, P.Eh. Hovsepian, L. Hultman, U. Helmersson, Comparison of microstructure and mechanical properties of chromium nitride-based coatings deposited by high power impulse magnetron sputtering and by the combined steered cathodic arc/unbalanced magnetron technique, Thin Solid Films 457 (2004) $270-277$.

[34] E.O. Hall, The deformation and ageing of mild steel: III discussion of results, Proc. Phys. Soc. London, Sect. B 64 (1951) 747.

[35] C.P. West, I. Harrison, E.J. Cussen, D.H. Gregory, Facile synthesis of bimetallic carbonitrides, $\mathrm{V}_{1-x} \mathrm{Ti}_{x}(\mathrm{C}, \mathrm{N})$, by microwave carbothermal reduction-ammonolysis/ carburisation (MW-CRAC) methods, J. Eur. Ceram. Soc. 29 (2009) 2355-2361.

[36] Z.L. Wu, J. Lin, J.J. Moore, M.K. Lei, Microstructure, mechanical and tribological properties of $\mathrm{Cr}-\mathrm{C}-\mathrm{N}$ coatings deposited by pulsed closed field unbalanced magnetron sputtering, Surf. Coat. Technol. 204 (2009) 931-935.

[37] C.-Y. Tong, J.-W. Lee, C.-C. Kuo, S.-H. Huang, Y.-C. Chan, H.-W. Chen, J.-G. Duh, Effects of carbon content on the microstructure and mechanical property of cathodic arc evaporation deposited CrCN thin films, Surf. Coat. Technol. 231 (2013) $482-486$.

[38] N. Schalk, J.F. Fotso, D. Holec, G. Jakopic, A. Fian, V.L. Terziyska, R. Daniel, C. Mitterer, Microstructure, mechanical and optical properties of TiAlON coatings sputter-deposited with varying oxygen partial pressures, J. Phys. D. Appl. Phys. 49 (2016) 025307(9 pp.).

[39] L. Shan, Y. Wang, J. Li, J. Chen, Effect of $\mathrm{N}_{2}$ flow rate on microstructure and mechanical properties of PVD $\mathrm{CrN}_{\mathrm{x}}$ coatings for tribological application in seawater, Surf. Coat. Technol. 242 (2014) 74-82.

[40] A. Riyadh, Al-S. Haftirman, K.R. Ahmad, Y. Al-Douri, The influence of roughness on the wear and friction coefficient under dry and lubricated sliding, Int. J. Sci. Eng. Res. 3 (2012) 1-6.

[41] A. Gilewicz, B. Warcholinski, Tribological properties of $\mathrm{CrCN} / \mathrm{CrN}$ multilayer coatings, Tribol. Int. 80 (2014) 34-40. 